\title{
Notes from Rocanville
}

\section{E. SYMONS}

I have picked up a couple of anecdotes which will be probably new to many members as they were to me.

One of my shop men told me this one:

Lawrence Dixon, of this district, observed a Hummingbird's nest built on a branch of a small poplar. It looked like a thimble and appeared to be of similar material of a wasp nest. The interesting thing was that he observed they en arge the nest as the family grows in order to provide sufficient accommodation.

\section{A Remarkable Lily}

Charles Thacker, Broadview, Sask.

While out for a drive early in July, Mrs. Thacker and I observed what appeared to be a large ball-shaped red flower. We turned around and went back to investigate. It turned out to be a clump of Red Lilies, all on one stem. From one side of the group to the other measured seven inches one way and six inches the other. The entire group made almost a perfect circle.

The thing that amazed us was that there were nine lilies in the group. I cannot recall seeing more than three or four on one stalk previously, and wondered if any one had seen a similar sight.

The one stalk at the top measured one quarter of an inch each way and was roughly rectangular shaped, but the stalk had five distinct ridges in it, as if five stalks grew in one.

\section{Floral Emblem is Endangered}

(From a July issue of the Regina Leader Post)

The Red Prairie Lily, Saskatchewan's floral emblem, is being picked indiscriminately by the thousands in the Pas, Manitoba, area for sale to
Another friend told me this:

A year or two ago he was duck hunting somewhere N.E. of Moose Jaw. It was late fall-the sloughs were frozen up but the ice was crystal clear. He saw a muskrat take off under the ice, so decided to verify just how he got air, and followed him. After a short swim he came up under the ice, exhales, waits a few moments, inhales again and swims off. He noted that the nearest airhole was about 200 yards away, and foilowing the 'rat, noted that it went through the same performance four or five times in the total distance.

tourists, a Yorkton couple reported after spending a holiday in that district.

The salesmen are young Indian boys and girls who pick the briliant flowers in large bunches and stand on the roadsides, north of The Pas, offering them for a few pennies to passing tourists.

\section{The Louse Fly}

Arthur Ward, Swift Current

While banding a thrush, a Louse Fly, slightly bronze in color, rather more flatish than the House Fly, jumped from the bird to my fingers then quickly back to the bird, disappearing in the feathers. Again, when banding an immature Yellow Warbler recently, this again was repeated.

Searching among the feathers revealed nothing. This same bird was captured twice later but the louse could not be found. Having seen this on four different birds and examining several others, it would seem that only when the louse jumps from the bird to the hand is it possible to see it.

The Louse Fly is a species of Ornithomyia and is a biood-sucking insect. 